\title{
Estatuto paradoxal da pele e cultura contemporânea: da porosidade à pele-teflon
}

Maria Cristina Franco Ferraz

Resumo: A exploração do estatuto paradoxal da pele - interface dentro/fora - permite ultrapassar a dicotomia metafísica superfície/profundidade, problematizando a tendência atual, também expressa na teoria, a um elogio das superfícies e a um horror por oposições dicotômicas. Possibilita avaliar as implicações do fechamento da porosidade da pele em formas de sociabilidade estimuladas na cultura da imagem, da exibição, do espetáculo, bem expressas pelo material inorgânico teflon. Sendo Poros, na visão grega, pai de Eros, a investigação acerca do estatuto paradoxal da pele convida a uma retomada do tema do erotismo. Partindo de perspectivas oferecidas por Agamben acerca da pornografia, ligada ao valor de exibição nas sociedades de espetáculo e de consumo, e relacionando-as a diversas reflexões de José Gil acerca do corpo e da pele, discute-se e convoca-se a abertura da porosidade da pele.

Palavras-Chave: paradoxos da pele; espetáculo e consumo; pornografia e erotismo.

Abstract: The paradoxical status of skin and contemporary culture: from the porosity of skin to Teflon skin - A theoretical approach to the paradoxical status of skin is a useful means to go beyond the metaphysical dichotomy of superficiality/depth, and to discuss the contemporary tendency to praise surfaces while rejecting any kind of dichotomousness. Establishing the conceptual notion of the paradoxical porosity of skin serves as a starting point from which it is possible to evaluate ways and forms of sociability fostered by today's culture of image, exhibition and spectacularity. The closing of the skin's pores emulates the characteristics of an inorganic material known commercially as Teflon. In Greek mythology, Poros is the father of Eros; hence, the investigation of the skin's porosity evokes the theme of eroticism. Exploring Agamben's approach to pornography and José Gil's reflections about the body, dance and skin, this article discusses some implications of the opening of the pores and the production of what we call Teflon skin.

Keywords: paradoxical status of skin; spectacularity and consumption; pornography and eroticism. 
A pele que acreditamos fechar e "conter" nossos corpos é dotada de um estatuto paradoxal que se torna cada vez mais oportuno tematizar, no contexto da expansão e consolidação da cultura da imagem, do espetáculo, da performance bem-sucedida e dos modos de vida com ela compatíveis. De início, lembremos que a pele é meio de comunicação por excelência, verdadeira interface dentro/fora, membrana de trânsito e trocas com o que costumamos chamar de "meio ambiente". Não se trata, portanto, de um mero "invólucro" ou "embalagem". Como lembrou oportunamente o filósofo português José Gil, em seu livro sobre corpo e dança, a própria sensação de tato se dá, na verdade, milímetros abaixo da pele:

Lembremos que a pele não é uma película superficial, mas que tem uma espessura, prolonga-se indefinidamente no interior do corpo: é por isso que a sensação de tato se localiza a alguns milímetros no interior da pele, e não à sua superfície. (GIL, 2001, p. 76; grifo do autor)

Segundo Gil, portanto, a pele tampouco termina lá onde a situamos, como uma espécie de traçado, de fronteira ou linha de cesura. Prolonga-se na verdade muito além do espaço no qual geralmente a circunscrevemos. Na perspectiva que concebe a pele em seu estatuto paradoxal, instaura-se uma noção de "dentro", do "interior" do corpo radicalmente diversa da usual, inaugurando-se uma visão de interior que já não se opõe ao exterior, sendo produzido em continuidade (um contínuo indiscernível) com a superfície porosa da pele.

Lembremos também que, se podemos ser tocados de modo indolor, tal se dá exatamente porque nossa pele possui essa textura paradoxal: a de uma superfície dotada de certa profundidade. Por isso também ela é sempre renovada, ao mesmo tempo viva "em profundidade" e "superficialmente" morta, nela se embaralhando a oposição nítida entre vida e morte. Como se sabe, a descamação ininterrupta e cotidiana de nossas peles, em certas condições climáticas tropicais, fornece alimento para gulosos pequenos seres como os ácaros, que vivem (e se reproduzem) em nossas camas enquanto dormimos em paz.

Em outro livro, o autor (GIL, 1997) explicita ainda mais essa outra versão do "interior", do "dentro", implicada na reflexão sobre o estatuto paradoxal da pele. Vale a pena reler ao menos esta passagem em que o autor recorre a um vocabulário apto a se afastar de simplificações espacializantes:

(...) esta zona fronteiriça tem realmente uma interface paradoxal: por um lado limita-se por fora graças à pele; por outro, prolonga o espaço da pele para dentro, conferindo à pele um espaço que a continua, transformando-a: não é já superfície, mas "volume" ou, mais exatamente atmosfera. (GIL, 1997, p. 155, grifo do autor) 
Essa dimensão paradoxal e membranosa, essa atmosfera ${ }^{1}$ de trocas e comunicação é, entretanto, recalcada em nossa própria compreensão e merece ser tratada no campo da teoria da comunicação, especialmente quando se deseja investigar as implicações das formas de sociabilidade estimuladas contemporaneamente. O esquecimento dos paradoxos da pele articula-se sem dúvida, no Ocidente, à noção incorporada (literalmente) de indivíduo, que convoca uma dialética entre dentro e fora de que tem sido difícil escapar.

Pensar as relações de um corpo com o que estaria "fora" supõe o pressuposto segundo o qual nossos corpos "próprios" (noção cara à tradição fenomenológica) seriam isoláveis do entorno (social, natural, cultural), e com ele se comunicariam a partir de sua separação. Nessa perspectiva, torna-se inevitável que a pele seja pensada (e vivida) como corte e afastamento entre dentro e fora, constituindo uma divisão nítida entre o eu e o mundo. Deixa-se de pensá-la, assim, em sua dimensão intrinsecamente comunicacional, como meio circulante de trocas de afetos e de forças do/no mundo.

Ora, a corrosão radical dessas premissas - tanto as do indivíduo quanto às do corpo próprio, do eu de certo modo isolável - nos foram legadas por alguns filósofos e poetas desde o século retrasado. Nesse sentido, a grande referência seminal permanece Nietzsche (1988). Com seu tema da profundidade da pele, o filósofo alemão corroeu a dialética dentro/fora, rebatida sobre o par antinômico profundidade/superfície. Denunciando a valorização tradicional da profundidade em detrimento da superfície - e o próprio estabelecimento de dualismos dicotômicos como tática para depreciar um dos polos da oposição -, Nietzsche apostou na pele.

Nela encontrou um potente aliado na empreitada de ultrapassagem da operação metafísica fundamental: inventar dicotomias para negar este mundo, esta vida, esta terra. Sua perspectiva estratégica se expressou exemplarmente no prólogo à Gaia ciencia, belamente concluído com a seguinte interpretação da cultura grega antiga, utilizada como arma de combate ao platonismo persistente em muitas de nossas crenças, práticas e valores:

Oh, esses gregos! Eles entendiam do viver! Para isto é necessário permanecer valentemente na superfície, na dobra, na pele, adorar a aparência, acreditar em formas, em tons, em palavras, em todo o Olimpo da aparência! Esses gregos eram superficiais - por profundidade! (NIETZSCHE, 2001, p. 15; grifo do autor)

A afirmação "superficial por profundidade" implica a corrosão interna e a implosão do dualismo metafísico, montado para acusar o superficial de pouco profundo, na medida em que o trata como mero negativo daquilo que teria valor (a profundidade). O tema nietzschiano da profundidade da pele marcou o século $X X$, sendo reeditado, por exemplo, pelo poeta francês Paul Valéry, para quem "o que há de mais profundo no homem é a pele" (VALÉRY, 1960, p. 215; tradução do autor). Ou na releitura da história

1 Essa noção é sem dúvida inspirada no belo trabalho de Damisch acerca das nuvens na história da pintura, também utilizado por Gil no livro sobre dança. Cf. DAMISCH (1972). 
de Robinson Crusoé, proposta por Tournier, no instigante romance intitulado Sexta-feira ou os limbos do Pacífico (TOURNIER, 1985), ao qual Deleuze dedicou um breve ensaio (DELEUZE, 1969, p. 350-372). Nessa ficção, sozinho na ilha, Robinson Crusoé põe em xeque o sentido da valorizada noção de profundidade, em expressões como "um espírito profundo", "um amor profundo". Eis o que discute, sintetizando a recusa (de matiz nietzschiano) à metafísica da profundidade:

\begin{abstract}
Estranha prevenção essa que valoriza cegamente a profundidade à custa da superfície e que faz com que "superficial" signifique não "de vasta dimensão", mas "de pouca profundidade", enquanto "profundo" significa, pelo contrário, "de grande profundidade" e não "de fraca superfície". E, no entanto, um sentimento como o amor mede-se bem melhor - se é que pode ser medido - pela importância de sua superfície do que pelo seu grau de profundidade. Pois eu meço o meu amor por uma mulher pelo fato de que amo igualmente suas mãos, os seus olhos, seu modo de andar, as roupas que usa, seus objetos familiares, aqueles que sua mão aflorou, as paisagens onde a vi evoluir, o mar onde se banhou... Tudo isso é bem superfície, parece-me! Enquanto um sentimento medíocre visa diretamente, em profundidade, o próprio sexo e deixa todo o resto em uma penumbra indiferente. (TOURNIER, 1985, p. 60-61; grifo do autor; tradução revista pelo autor)
\end{abstract}

O pensamento contemporâneo, em especial aquele frequentemente denominado como "pós-moderno", parece ter absorvido essa discussão, expressando por vezes um horror superficial (não por profundidade) ante toda e qualquer lógica dicotômica. A valorização da superfície também foi capturada e apropriada pelas "alegrias do marketing" (DELEUZE, 1992, p. 226) nos mais diversos campos, não deixando de contaminar inclusive a produção teórica e acadêmica. Contrabandeando a visada nietzschiana, o mero elogio da superfície - de uma superfície purificada desse jogo paradoxal com a profundidade - pode então derivar em uma crítica a qualquer profundidade, mesmo àquela (radicalmente antimetafísica) reinventada por Nietzsche. Mais um bom motivo para distinguirmos sentidos divergentes, em nada equivalentes, do gesto de requalificação da superfície em detrimento da profundidade.

Em Nietzsche não se trata de uma simples inversão de termos (valorizar a superfície, em vez da profundidade), pois, como mostra sua filosofia, toda inversão permanece refém do mesmo campo de pensamento. O que está em jogo é uma transvaloração dos termos, a superação do solo mesmo em que emergem as dicotomias, o que convoca geralmente uma lógica paradoxal. Por isso, e seguindo superficial-profundamente a lição nietzschiana, é mais do que oportuno, parece-me mesmo necessário avaliar atualmente concepções distintas de superfície e de profundidade, ou melhor, estimar o jogo estabelecido entre esses termos e suas implicações. Por isso, a tematização do estatuto da pele e seu tratamento pelo viés do paradoxo me parecem duplamente incontornáveis: tanto quando se investigam 
formas de sociabilidade estimuladas em nosso tempo quanto quando se pretende afastar de uma adesão apressada ao senso comum pós-moderno, da rejeição em bloco de toda dicotomia ou de qualquer profundidade.

Para avançarmos na exploração dos vínculos entre estatuto paradoxal da pele e formas de sociabilidade, retomemos algumas observações efetuadas por Gil em um terceiro livro, intitulado Portugal, hoje - o medo de existir. Quando Gil comenta os efeitos sobre a pele do regime de vida dos corpos hiperconectados tecnologicamente, sempre em trânsito frenético, ele compõe um quadro que concerne aos modos de vida e de circulação demandados aos que se inserem na lógica do controle (DELEUZE, 1992) própria ao capitalismo turbinado. Vejamos um trecho do livro em que se introduz o tema, a ser desdobrado na sequência:

Circular por entre pequenas coisas, investir nelas e logo desinvestir, conectar-se e a seguir desconectar-se dá a ilusão de movimento, de liberdade, de um desejar diverso, rico, múltiplo. [...] Movimento realmente ilusório, pois esse saltitar de uma pequena coisa para outra não faz senão escamotear o sentido de uma inscrição que prolonga outra inscrição. (GIL, 2004, p. 52; grifo do autor)

O termo "inscrição", de matriz gráfica, e tomado à psicanálise, remete aqui à porosidade de uma pele aberta a fluxos de trocas e afetos. É essa inscrição que tende a ser curtocircuitada nesse movimento acelerado, na imediatez de um incessante conectarse e desconectar-se, como que alisando (ou digitalizando) a pele, fechando-lhe os poros. Nessa pele lisa os possíveis encontros parecem tão-somente esbarrar para escorrer. A sensação de deslizar sobre superfícies lisas tem por efeito bloquear a penetração nos poros e a inscrição efetiva de acontecimentos no corpo.

Esse movimento deslizante e contínuo, o funcionamento ondulatório, orbital, já tinha sido apontado por Deleuze nos breves textos sobre o controle do início dos anos 1990 (que soam tão antecipatórios). Neles Deleuze articula o controle (que é um conceito, não um termo banal) à prática do surf (DELEUZE, 1992, p. 223). Claro que, em seus comentários, o filósofo francês trata do tema de modo aberto, sugerindo tanto as novas dores quanto as delícias dos modos de vida a que somos convidados a aderir. Mas, ao se tratar de pele, esse escorregar constante e acelerado tende, sobretudo, a lacrar os corpos sensível e afetivamente. Retomando Gil, eis o que o filósofo português prossegue analisando:

Cria-se um circuito em que a inscrição (por exemplo, de um pequeno prazer) parece efetuar-se na pequena coisa, no ato que a elege; logo depois o desejo salta para outra pequena coisa, desapegando-se dela com a mesma facilidade com que a outra se apega. [...] E assim se vai, de uma tarefa a outra, de um empreendimento a outro, de um afeto a outro, de um pensamento a outro. Sempre saltitando, em trânsito permanente para parte nenhuma. (GIL, 2004, p. 52) 
Como se pode observar, não se trata apenas de velocidade ou de aceleração, mas de uma incitação à rapidez e imediatez de conexões e desconexões, produzindose um esquecimento adequado à descartabilidade, a uma deletabilidade generalizada, inerente à lógica da obsolescência programada de mercadorias, relações e modos de ser. Esse circuito acelerado tem por efeito compactar e comprimir a temporalidade vivida que, como sabemos, desde Bergson, flui dotada de certa espessura indivisível e contínua, designada pelo conceito de duração (BERGSON, 2006).

De um descarte a outro, esgarça-se a sensação de continuidade, corroendo-se a possibilidade do sentido e a sedimentação do vivido, sob o modo da experiência. Ressalte-se também o peso da pequenez na citação acima: nessa velocidade conectante/ desconectante, esbate-se qualquer relevo, produzindo-se o achatamento e nivelamento de possíveis intensidades. Contrabandeando um termo significativamente apropriado da esfera dos negócios, pode-se dizer que tende a ocorrer um desinvestimento afetivo e existencial da pele. Constitui-se um corpo carapaça, um corpo-fortaleza vazia, que, segundo Gil, já não consegue se expandir e dilatar-se, "evoluindo num espaço 'liso', sem obstáculos, aparentemente sem regras [...] livremente, fechados sobre si, isolados [...]" (GIL, 2004, p. 121).

Ainda uma vez, vejamos o diagnóstico traçado por Gil: "É o corpo afetivo que se esvaziou. [...] O espaço de circulação está disponível (e a 'liberdade' também), mas perdeu a qualidade, a singularidade e a abertura. Já não é um espaço de possíveis, mas a circulação de zombies" (ibid., p. 121).

Em seu fechamento, esses zumbis eficientes, acelerados, proativos, hiper e interconectados incorporaram as qualidades próprias a um material inorgânico que frequenta nosso cotidiano e que bem expressa o surfar competente sobre superfícies escorregadias: o teflon. Esse é o nome comercial de um polímero acidentalmente descoberto na década de 1930 (o politetrafluoretileno), que foi registrado pela empresa americana DuPont e patenteado em 1946.

Com um pequeno esforço de memória, podemos nos lembrar como era fritar um ovo antes do teflon, tendo de colocar muito óleo ou manteiga na frigideira para não grudar. Diante de nossos olhos desenrolava-se então um verdadeiro embate épico, em função da resistência e viscosidade próprias ao orgânico. Já em uma frigideira teflon, qualquer possível drama se desfaz: os ovos parecem surfar sobre o deslizante material inorgânico, sem atrito ou necessidade de mediação.

Essas características do teflon - material com o mais baixo coeficiente de atrito e maior grau de impermeabilidade - repercutem nas superfícies fechadas e deslizantes dos corpos-carapaça. Para as "alegrias" do marketing² e do capital, nada mais adequado do que aquilo que não provoca atritos; nada mais conveniente do que impermeabilidades ambulantes.

2 Inevitável lembrar o filme chileno No (2012), de Pablo Larraín, indicado ao Oscar de melhor filme estrangeiro. Nele se mostra, com argúcia, de que forma a promoção da alegria, apropriada pelo discurso publicitário, pode servir paradoxalmente como instrumento midiático para o fim da ditadura de Pinochet, exatamente na medida em que também veicula e consolida um novo tipo de ditadura mais compatível com a flexibilidade e elasticidade requeridas pela sociedade do espetáculo e do consumo, pouco afeita à sisudez e ao enrijecimento dos corpos e da corporação militar - que simplesmente "não vendem". 
Nesse modo teflon de viver e de se movimentar, os corpos vão deixando de se afetar ou aderir mutuamente. Tem-se a sensação igualmente ilusória de "liberdade", de uma liberdade aliada a um desejo que em nada se detém, não consegue mais se fixar, tornando-se progressivamente impermeável a ligações duradouras de pertencimento e afeto. Trata-se de uma "liberdade" que funciona como novo imperativo (ROSE, 2007), como coerção, como já percebia com agudeza o instigante macaco que, em Kafka, relata sua experiência de humanização a uma academia científica.

No texto Um relatório para uma Academia (KAFKA, 1999), o macaco-homem explica ter escolhido humanizar-se não para realizar o sonho iluminista de "liberdade", mas para encontrar alguma "saída" (Ausweg, literalmente em alemão, "caminho para fora"). Quando a liberdade se torna imperativa - liberdade de ter de escolher em um amplo e crescente mercado, desmunido das balizas de critérios tradicionais -, trata-se de encontrar saídas: exatamente poros, no sentido grego antigo.

Os gregos antigos articularam de modo significativo o tema das saídas para situações de impasse ao erotismo. Nesse sentido, um breve retorno às origens gregas de Poros e de Eros pode revelar-se relevante para afinar nossa temática. Como nos ensina o Dicionário de mitologia grega e romana de Grimal (1951), Poros, Expediente, é filho de Métis, primeira esposa de Zeus, que a engoliu por temê-la, já que se tratava da divindade que presidia à Astúcia. Como um deus cioso por garantir seu reinado, Zeus precisava se precaver contra uma esposa astuciosa. O nome de Poros foi incorporado ao vocabulário filosófico, que caracteriza como aporia (termo composto por poros acrescido do prefixo privativo grego a-) qualquer situação sem saída ou de impasse. Como filho da Astúcia, Poros é o expediente, o "jeitinho" que se vislumbra para encontrar alternativas e saídas em situações difíceis ou embaraçosas.

O mais curioso é como Poros está intimamente ligado a Eros, especialmente na versão do mito proposta pela sacerdotisa Diotima, que toma a palavra no diálogo platônico O banquete (PLATÃO, 1973). Segundo Diotima, Eros é um ser intermediário entre os deuses e os homens, fruto da união de Penia (Pobreza) com Poros. Eis a deliciosa história: não tendo sido convidada para um banquete dos deuses, Penia se aproveita do sono de Poros, que dormia saciado nos jardins, e engendra Eros, resultado portanto do enlace entre a Pobreza e o Expediente. Seguindo a sugestão, legada pelos gregos, desse íntimo parentesco entre Poros e Eros, podemos avançar a hipótese de que a despotencialização da profundidade paradoxal da pele e o bloqueio da porosidade afetam a circulação de Eros nos corpos.

Um dos caminhos para se tematizar os vínculos entre poros e eros na cultura da imagem e do espetáculo nos remete a certas hipóteses traçadas por Agamben ao final do livro Profanações (AGAMBEN, 2005, p. 91-106). O percurso, embora um pouco longo, merece ser trilhado, mesmo que de modo sintético. Agamben retoma um fragmento póstumo de Walter Benjamin (intitulado O capitalismo como religião) para enfatizar que, segundo o filósofo alemão, o capitalismo não representaria, tal como na tese clássica de Weber, 
uma secularização da fé protestante, mas seria a própria religião da modernidade. Como religião cultural, o capitalismo não visaria à transformação do mundo, mas à sua destruição.

A esfera do consumo, do espetáculo, como fase extrema do capitalismo, corrói a tensão entre valor de troca e valor de uso, que caracaterizava o fetichismo da mercadoria, estabelecendo a impossibilidade radical do próprio uso. Por isso Agamben elege o museu, a museificação do mundo (e o turismo) como expressões do esvaziamento progressivo das potências espirituais que já definiram a vida dos homens (arte, religião, filosofia, política). Considera conceitualmente museu não como espaço físico, mas como o termo que nomeia "a exposição de uma impossibilidade de usar, de habitar, de experienciar" (ibid., p. 96).

$\mathrm{Na}$ passagem que nos interessa mais diretamente, Agamben assinala que esse descolamento do puro meio, exibido na esfera midiática, expõe o vácuo, exibe o vazio, barrando a via a qualquer outro uso novo, a uma outra experiência de palavra. Remete então a nulificação dos puros meios à pornografia. O autor lembra que nos primórdios da fotografia erótica as modelos costumavam ostentar expressões românticas, quase sonhadoras, como se a câmera as tivesse surpreendido na intimidade de seus boudoirs (ibid., p. 102).

Mas logo as poses e expressões se alteram, acompanhando o que Agamben chama de "absolutização capitalística da mercadoria e do valor de troca" (ibid., p. 103): as modelos passam a exagerar intencionalmente a obscenidade, exibindo diretamente sua consciência de estarem expostas à câmera. Em seus gestos mais íntimos, as pornostars - acrescenta Agamben - fixam de modo resoluto e (literalmente) descarado a câmera, infletindo seu interesse do(a) parceiro(a) em direção aos espectadores. Duplicação portanto da indiferença e da obscenidade, em uma das etimologias latinas possíveis da palavra: ob scenus, fora da cena.

Essa mudança também já se insinuava na pintura moderna: basta lembrar o quadro de Édouard Manet intitulado Olympia (1863), que causou escândalo não por sua nudez (o tema e a postura tradicionais remetem às Vênus de Ticiano e de Giorgione), mas pela desfaçatez do olhar direto do corpo-manequim da jovem prostituta. Ests olhar encara e interpela o espectador-burguês, que, embora também cliente, circula com suas famílias no espaço nobre das exposições de arte. A fria indiferença do olhar de Olympia afirma e exibe despudoradamente sua condição de mercadoria. Como já amplamente observado em história da pintura, a mão pousada no sexo em Olympia é a única parte da pintura em relevo, enquanto o corpo branco e nu avança agressivamente sobre o espectador de modo direto, em nada velado. A mão simplesmente tapa (e assinala) o alvo da transação comercial, oculto na tela, mas ao mesmo tempo pictoricamente enfatizado. A nudez não é a do corpo, mas a de um rosto branco, indiferente, em que se crava um olhar frio, impassível. Um rosto que uma fitinha de veludo destaca do corpo exposto, como que separando a mercadoria e o balcão do negociante. O que se desnuda em Olympia são as convenções culturais, pictóricas e sociais que mantinham a nudez no campo do sublime, do idealizado, do sagrado, distante do mundo prosaico e desglamorizado da mercadoria. 
No texto referido, Agamben resgata ainda o conceito benjaminiano de "valor de exibição" (Ausstellungswert), cunhado no famoso ensaio sobre a reprodutibilidade técnica. Entre os termos marxistas "valor de troca" e "valor de uso", introduz-se um terceiro termo: o "valor de exibição". Sublinha que é no rosto humano que esse valor de exposição encontra seu locus privilegiado. Com efeito, a consciência de estar sendo visto funciona como um potente desagregador dos processos expressivos que em geral animam o rosto humano (ibid., p. 104).

O autor destaca a ostentação da indiferença buscada pelos profissionais da exposição, sejam eles pornostars ou topmodels. O imperativo do espetáculo, que em Débord (1992) se equacionava pela intermediação incontornável de imagens nas relações consigo e com o outro, adquire uma circularidade tautológica no enunciado proposto por Giorgio Agamben: "não dar a ver nada além do que um dar a ver (ou seja, a própria e absoluta medialidade)" (Agamben, 2005, p. 104).

Em um movimento que não deixa de aparentar-se ao de certos ensaios benjaminianos, Agamben assinala, nessa nulificação da expressividade, uma porta de entrada para o erotismo nesse lugar que escapa à nudez por ser sempre já nu: o rosto humano. Liberto da expressividade, o rosto tornar-se-ia disponível para um "novo uso, para uma nova forma de comunicação erótica" (ibid., p. 105).

As pornostars não simulam prazer, segundo antigas convenções do gênero; afetam e exibem indiferença total, tanto por seu partner quanto, por tabela, pelos espectadores. Mas talvez por isso mesmo sejam atrativas. A impassibilidade do rosto dissolve o vínculo entre o vivido e a expressão, dando-se a ver como puro meio. Segundo Agamben, justamente aí residiria seu potencial profanatório, sua potencia para inaugurar novos usos possíveis - um novo uso coletivo da sexualidade (ibid., p. 106) -, bloqueados entretanto, desviados e neutralizados pelo que o autor chama de "dispositivo da pornografia".

Mesmo que se abra a possibilidade de novas circulações de Eros, esta se encontra barrada: eis o diagnóstico de Agamben. Sem entrar em consideração a respeito do conceito de dispositivo (tomado a Foucault e Deleuze) ou, mais especificamente, de "dispositivo da pornografia", mantém-se a hipótese segundo a qual o valor de exibição do corpo-mercadoria curtocircuita Eros.

Retomando Deleuze e Guattari, Gil lembra que o desejo se expressa em uma só palavra-agenciar (GIL, 2001, p. 70) -, funcionando como agenciamento de agenciamentos. Uma passagem do livro sobre corpo e dança permite desdobrar com maior precisão as relações entre pele e desejo:

Este corpo paradoxal abre-se e fecha-se sem cessar ao espaço e aos outros corpos. Capacidade que se prende menos com a existência dos orifícios que o marcam de forma visível do que com a natureza da pele. Porque é mais por toda a superfície da pele que através da boca, do ânus ou da vagina que o corpo se 
abre ao exterior. Esses orifícios estão a serviço de funções orgânicas de trocas entre o interior e o exterior. Mas raramente operam a abertura global do espaço interno (excepto no prazer sexual e na fala). (GIL, 2001, p. 69)

Nesse trecho, Gil ressalta a diferença qualitativa entre os orifícios do corpo (boca, ânus, vagina) e a extensão erotizável de toda a pele, com sua atmosfera ou "espaço interno". Enquanto nesses orifícios os ditames orgânicos sobredeterminam o fluxo de forças, a potencia extensiva e intensiva da pele (mas também da fala e do prazer sexual) permite uma circulação de Eros dilatada e infinita, escapando de qualquer inflexão "para dentro".

Como o filósofo comenta no livro sobre dança, é por isso que o movimento dançado fecha os orifícios, criando uma superfície contínua de "espaço-pele" que impede "que os orifícios induzam movimentos em direção ao interior do corpo" (GIL, 2001, p. 7879). Observe-se que, nesse trabalho de Gil, se esclarece de modo luminoso o difícil conceito deleuzeano, (extraído de Antonin Artaud) de corpo sem órgãos (DELEUZE, 1980, p. 185-204). Por isso também é que o corpo nu do bailarino, seja ele clássico ou contemporâneo, dissolve os traços dos órgãos genitais para dar a ver e enfatizar a "continuidade da superfície única da pele, não deixando [...] os órgãos do interior manifestarem-se ou tornarem-se visíveis" (ibid., p. 79). Todo o contrário das mercadoriasOlympia, que concentram, sugam e fixam as energias do olhar e do corpo do espectador no ponto único e convergente daquilo que vende.

Essa produção de uma superfície ampliada, erotizada e intensiva é buscada por várias experiências estéticas contemporâneas, da dança às performances e artes visuais. A abertura da porosidade da pele é uma das forças de combate às carapaças teflon dos corpos fechados, em trânsito para lugar nenhum. A exploração desse tema funciona, igualmente, como um convite à abertura dos corpos. Eis o endereçamento filosófico de uma teoria da comunicação dirigida para o diagnóstico crítico do que estamos nos tornando: a ativação da porosidade do corpo como interface dentro/fora. Essa é a aposta que, ao fim e ao cabo, subjaz igualmente a este trabalho.

Maria Cristina Franco Ferraz é professora titular de Teoria da Comunicação da UFF (aposentada) e da Escola de Comunicação da Universidade Federal do Rio de Janeiro (ativa), pesquisadora do CNPq, doutora em Filosofia pela Universidade de Paris I - Sorbonne (1992), com três estágios de pós-doutoramento em Berlim (Instituto Max Planck de História da Ciência, em 2004, e Centro de Pesquisa em Literatura e Cultura, em 2007 e 2010). Coordenou na UFF o Doutorado Internacional Erasmus Mundus "Cultural Studies in Literary Interzones". Publicou os seguintes livros: 
Nietzsche, o bufão dos deuses: Platão: as artimanhas do fingimento; Nove variações sobre temas nietzschianos e Homo deletabilis - corpo, percepção, esquecimento: do século XIX ao XXI. Foi professora visitante em diversas universidades nos EUA e Europa.

mcfferraz@hotmail.com

\section{Referências}

AGAMBEN, Giorgio. Profanazioni. Roma: Nottetempo, 2005.

BERGSON, Henri. Matéria e memória. São Paulo: Martins Fontes, 2006.

DAMISCH, Hubert. Théorie du nuage - pour une histoire de la peinture. Paris: Editions du Seuil, 1972.

DEBORD, Guy. La société du spectacle. Paris: Gallimard, 1992.

DELEUZE, Gilles. "Michel Tournier et le monde sans autrui". In: Logique du sens. Paris: Editions Minuit, 1969.

Mille plateaux. Paris: Editions Minuit, 1980.

Conversações. Rio de Janeiro: Ed. 34, 1992.

GIL, José. Metamorfoses do corpo. Lisboa: Relógio D’Água, 1997.

Movimento total: o corpo e a dança. Lisboa: Relógio D'água, 2001.

Portugal, hoje - o medo de existir. Lisboa: Relógio D'Água. 2004.

GRIMAL, Pierre. Dictionnaire de la mythologie grecque et romaine. Paris: PUF, 1951.

KAFKA, Franz. Um médico rural. São Paulo: Companhia das Letras, 1999.

NIETZSCHE, Friedrich. Sämtliche Werke. Berlim/Nova York: DTV/de Gruyter, 1988, 15 vol.

A gaia ciência. Tradução, notas e posfácio de Paulo César de Souza. São Paulo: Companhia das Letras, 2001.

ROSE, Nikolas. The politics of life itself (biomedicine, power, and subjectivity in the twenty-first century. Princeton: Princeton University Press, 2007.

PLATÃO. Le banquet. Paris: Gallimard, 1973.

TOURNIER, Michel. Sexta-feira ou os limbos do Pacífico. Tradução de Fernanda Botelho. São Paulo: Difel, 1985.

VALÉRY, Paul. "L'idée fixe". In: Oeuvres complètes. Tome II. Paris: La Pléiade, 1960. 